\title{
Notas Científicas \\ Crescimento micelial de Pleurotus ostreatus em resíduo de Simarouba amara
}

\author{
Ceci Sales-Campos ${ }^{(1)}$, Augusto Ferreira da Eira(2), Maria Aparecida de Jesus ${ }^{(1)}$, \\ Francielli Campagnolli ${ }^{(1)}$ e Meire Cristina Nogueira de Andrade ${ }^{(1)}$
}

\begin{abstract}
(1)Instituto Nacional de Pesquisas da Amazônia, Coordenação de Pesquisas de Produtos Florestais, Caixa Postal 478, CEP 69060-001 Manaus, AM. E-mail: ceci@inpa.gov.br, ranna@inpa.gov.br, camp_fran@hotmail.com, meire@inpa.gov.br (2)Universidade Estadual Paulista, Departamento de Produção Vegetal, Caixa Postal 237, CEP 18610-307 Botucatu, SP. E-mail: augustoeira@fungibras.com.br
\end{abstract}

\begin{abstract}
Resumo - O objetivo deste trabalho foi avaliar o crescimento micelial do cogumelo Pleurotus ostreatus, cultivado na serragem da espécie madeireira Simarouba amara. Avaliaram-se: o efeito das temperaturas de 22, $25,27,30$ e $35^{\circ} \mathrm{C}$ sobre o crescimento micelial de P. ostreatus, nos meios malte-ágar 3\% e SDA-MA (infusão da serragem de $S$. amara, enriquecida com farelo de soja-dextrose-ágar); e o crescimento micelial em substrato de cultivo de serragem de $S$. amara, com e sem suplementação de farelo de soja, a 25 e $30^{\circ} \mathrm{C}$. O melhor desenvolvimento de $P$. ostreatus ocorreu em meio malte-ágar $3 \%$ a $25^{\circ} \mathrm{C}$. A suplementação de farelo de soja na serragem de $S$. amara favorece o crescimento micelial.
\end{abstract}

Termos para indexação: cogumelos comestíveis, cogumelo hiratake, crescimento micelial, serragem.

\section{Mycelial growth of Pleurotus ostreatus in Simarouba amara sawdust}

\begin{abstract}
The objective of this work was to assess the mycelial growth of oyster mushroom (Pleurotus ostreatus) cultivated in sawdust of Simarouba amara. Evaluations were made for the effect of temperatures 22, $25,27,30$ and $35^{\circ} \mathrm{C}$ on the mycelial growth of $P$. ostreatus in 3\% malt-agar and SDA-MA (infusion of $S$. amara sawdust, enriched with soybean meal-dextrose-agar) media; and the mycelial growth in cultivation substrate of $S$. amara sawdust, with and without supplementation of soybean meal, at 25 and $30^{\circ} \mathrm{C}$. The best development of $P$. ostreatus was in $3 \%$ malt-agar medium at $25^{\circ} \mathrm{C}$. Soybean meal supplementation on S. amara sawdust promoted mycelial growth.
\end{abstract}

Index terms: edible fungi, hiratake mushroom, mycelial growth, sawing.

Os resíduos gerados pela indústria madeireira, na Região Amazônica, têm causado poluição do meio ambiente, porém as indústrias madeireiras têm buscado soluções para o aproveitamento dos rejeitos (Sales-Campos et al., 2000).

A importância do cultivo de cogumelos é significativa, por representar alternativa eficiente para se viabilizar o aproveitamento desses resíduos. Os Pleurotus spp. são fungos degradadores de madeira e formam o grupo denominado fungos de podridão-branca (Maziero, 1990). De acordo com Nyochembeng et al. (2008), a utilização de fungos para a reciclagem de resíduos sólidos é vantajosa, uma vez que esses cogumelos comestíveis são produzidos a partir de um subproduto.

O cultivo comercial do fungo comestível $P$. ostreatus pode representar uma alternativa economicamente viável, com potencial de inserção no modelo industrial madeireiro regional, como também na pequena propriedade rural familiar. Torna-se, portanto, necessária a adaptação da tecnologia de produção às condições regionais de clima e de disponibilidade de resíduos.

Nas técnicas de cultivo são utilizados vários meios de cultura, para obtenção da matriz primária, para o cultivo de fungos comestíveis (Bononi et al., 1999). Todavia, há a necessidade de se avaliarem os melhores meios de cultura para os isolados, que não sejam divergentes das condições de cultivo em substrato (Andrade et al., 2008).

O objetivo deste trabalho foi avaliar a cinética micelial do fungo $P$. ostreatus, cultivado na serragem da espécie madeireira Simarouba amara, para se determinar a condição ótima de crescimento micelial.

Os experimentos foram conduzidos no Instituto Nacional de Pesquisas da Amazônia (Inpa), Coordenação de Pesquisas em Produtos Florestais, de abril a dezembro de 2005. 
A preparação da matriz primária foi realizada a partir do isolado de P. ostreatus, depositado no Laboratório de Patologia da Madeira, Inpa. A multiplicação do isolado fúngico foi realizada por meio de fragmentos do micélio, cultivados em meio de cultura à base de malte-ágar 3\% para meio BDA, conforme Bononi et al. (1999).

Para se avaliar a influência da temperatura no crescimento micelial de $P$. ostreatus, em meios de cultura (experimento 1), foram preparadas placas de Petri com malte-ágar 3\% (Bononi et al., 1999) e SDA-MA (infusão da serragem de $S$. amara - Marupá, enriquecida com farelo de soja-dextrose-ágar). No preparo do meio SDA-MA, utilizaram-se, em base seca, $100 \mathrm{~g}$ de composto por litro final de infusão, preparado com $90 \%$ de serragem, $8 \%$ de farelo de soja e $2 \%$ de $\mathrm{CaCO}_{3}$ (adaptado de Andrade et al., 2007). Após o preparo, o composto foi submetido à fervura em 1,5 L de água durante $30 \mathrm{~min}$. Em seguida, a infusão foi filtrada em algodão, e seu volume foi completado para $1 \mathrm{~L}$, tendo sido adicionados ao meio $12 \mathrm{~g}$ de dextrose e $15 \mathrm{~g}$ de ágar por litro. Ambos os meios foram autoclavados por $45 \mathrm{~min}$, a $121^{\circ} \mathrm{C}$ e $1 \mathrm{~atm}$ de pressão.

Após o preparo e solidificação dos meios de cultura, em placas de Petri, a avaliação do crescimento micelial radial foi conduzida conforme Maziero (1990). Para isso, as placas de Petri com os meios de cultura receberam discos de $9 \mathrm{~mm}$ de inóculo, em condições assépticas. A mensuração do crescimento micelial radial foram realizadas a cada 24 horas, durante 20 dias, e foram traçadas, na tampa de cada placa, duas retas perpendiculares. A média das duas medições foi registrada para cada leitura. Odiâmetro total da colônia foi calculado em razão do crescimento micelial final, obtido com a colonização do fungo na placa. $\mathrm{O}$ experimento foi conduzido em incubadora convencional a 22, 25, 27 , 30 e $35^{\circ} \mathrm{C}$, sem luz. O delineamento experimental foi inteiramente ao acaso, em esquema fatorial $5 \times 2$, com três repetições por tratamento.

Para se avaliar o crescimento micelial de $P$. ostreatus, em substrato de cultivo de serragem de $S$. amara, sem e com suplementação à base de farelo de soja (experimento 2), adicionou-se $\mathrm{CaCO}_{3}$ em torno de 3\% para ajuste do $\mathrm{pH}$ para 6,5. No caso de suplementação com farelo, utilizaram-se $85 \%$ de serragem, $12 \%$ de farelo e $3 \%$ de $\mathrm{CaCO}_{3}$. O substrato foi umidificado a $75 \%$, e porções de $25 \mathrm{~g}$ foram distribuídas em placas de Petri e autoclavadas a $121^{\circ} \mathrm{C}$, por 1 hora. Após o resfriamento, em condições axênicas, o substrato contido em cada placa foi infectado com a cultura de P. ostreatus, crescido em meio SDA-MA, em disco de $9 \mathrm{~mm}$ de diâmetro, posicionado no centro da placa, e foi incubado a 25 e $30^{\circ} \mathrm{C}$, sem luz. A mensuração foi realizada conforme relatado no primeiro experimento, com intervalos de 48 horas. O delineamento experimental foi inteiramente ao acaso, em esquema fatorial $2 \times 2$, com três repetições por tratamento.

As médias foram comparadas pelo teste Tukey, a 5\% de probabilidade, com o procedimento ANOVA, do programa Minitab for Windows 1.3.

Houve interação significativa entre os fatores meio e temperatura $(\mathrm{p}<0,05)$. O crescimento do $P$. ostreatus foi maior a $25^{\circ} \mathrm{C}$, em ambos os meios de cultura testados, e a combinação ótima de fatores ocorreu no meio malte-ágar $3 \%$ a $25^{\circ} \mathrm{C}$ (Tabela 1). Isso ocorreu, provavelmente, em razão de o meio malte-ágar 3\% ser mais rico em nutrientes, em comparação ao meio SDA-MA. Andrade et al. (2008), ao avaliar o crescimento micelial de duas linhagens de Lentinula edodes, a $25^{\circ} \mathrm{C}$, em dez tipos de meio de cultura, verificaram que o meio à base de extrato de serragem de Eucalyptus citriodora foi o mais promissor. Donini et al. (2005) avaliaram a velocidade de crescimento micelial de linhagens de Pleurotus spp., em diferentes substratos, e observaram diferenças significativas na interação entre linhagens, substratos e dias de avaliação.

Furlan et al. (1997) estudaram fungos que crescem em altas temperaturas, com o uso de diferentes meios de cultura e temperaturas, e observaram que, entre os meios estudados, o TDA (trigo-dextrose-agar) permitiu o melhor crescimento, e o fungo $P$. ostreatus obteve o melhor desempenho entre 20 e $30^{\circ} \mathrm{C}$. No presente trabalho, não houve crescimento micelial do fungo a $35^{\circ} \mathrm{C}$, nos meios de cultura testados. Resultados semelhantes foram obtidos por Nascimento \& Eira (2007), que verificaram que temperaturas de incubação, acima de $35^{\circ} \mathrm{C}$, inibiram completamente o crescimento

Tabela 1. Crescimento micelial radial de Pleurotus ostreatus (mm), nos meios de cultura malte-ágar 3\% e SDA-MA (infusão da serragem de Simarouba amara, enriquecida com farelo de soja-dextrose-ágar), em diferentes temperaturas, após 20 dias de incubação ${ }^{(1)}$.

\begin{tabular}{lccccc}
\hline Meio de cultura & \multicolumn{5}{c}{ Temperatura $\left({ }^{\circ} \mathrm{C}\right)$} \\
\cline { 2 - 6 } & 22 & 25 & 27 & 30 & 35 \\
\hline Malte-ágar 3\% & $5,96 \mathrm{Ac}$ & $15,96 \mathrm{Aa}$ & $7,27 \mathrm{Ab}$ & $3,18 \mathrm{Ad}$ & $0,27 \mathrm{Ae}$ \\
SDA-MA & $4,12 \mathrm{Bb}$ & $10,95 \mathrm{Ba}$ & $4,60 \mathrm{Bb}$ & $2,63 \mathrm{Ac}$ & $0,41 \mathrm{Ad}$ \\
\hline
\end{tabular}

${ }^{(1)}$ Médias seguidas de letras iguais, maiúsculas nas colunas e minúsculas nas linhas, não diferem entre si pelo teste Tukey, a 5\% de probabilidade. 
micelial de Diehlmyces microsporus. Zadrazil (1974), afirmou que, em temperaturas acima de $30^{\circ} \mathrm{C}$, há efeito nocivo a $P$. ostreatus e $P$. florida, e aos $40^{\circ} \mathrm{C}$ o efeito é letal, quando a espécie é exposta por período maior que 24 horas.

Observou-se que o crescimento do P. ostreatus, no substrato suplementado com farelo de soja, foi maior quando comparado ao não suplementado, nas temperaturas testadas (Tabela 2), o que evidenciou a importância da suplementação para a serragem. Porém, a serragem suplementada não apresentou crescimento diferenciado entre as temperaturas de 25 e $30^{\circ} \mathrm{C}$.

A suplementação em ambas as temperaturas promoveu melhor taxa de crescimento micelial do fungo (Tabela 2). Das \& Mukherjee (2007) avaliaram o uso de sete ervas daninhas, no cultivo de $P$. ostreatus, e verificaram que o Leonotis sp. foi o melhor substrato para o cultivo do P. ostreatus. Wang et al. (2001) verificaram que poucos cogumelos foram formados nos resíduos apenas com grãos de cevada, e que uma alta eficiência biológica foi obtida com a adição de farelo de trigo. No entanto, Baysal et al. (2003) relatam que o excesso de nitrogênio pode limitar o crescimento.

Um rápido crescimento micelial é importante, uma vez que reduz os índices de contaminações. Jonathan et al. (2008) verificaram que uma rápida colonização micelial do $P$. tuber-regium, nos seletivos substratos, tais como resíduos de madeira de Holoptelia grandis e Milicia excelsa, reduz consideravelmente o crescimento de outros organismos competidores.

A suplementação da serragem de Simarouba amara favorece o crescimento micelial e proporciona boa colonização pelo fungo $P$. ostreatus.

Tabela 2. Crescimento micelial radial de Pleurotus ostreatus (mm), em serragem de Simarouba amara, com e sem suplementação de farelo de soja, a 25 e $30^{\circ} \mathrm{C}$, após 20 dias de incubação ${ }^{(1)}$.

\begin{tabular}{lcc}
\hline Substrato de cultivo (serragem) & \multicolumn{2}{c}{ Temperatura $\left({ }^{\circ} \mathrm{C}\right)$} \\
\cline { 2 - 3 } & \multicolumn{1}{c}{25} & 30 \\
\hline Com suplementação & $10,12 \mathrm{Aa}$ & $12,83 \mathrm{Aa}$ \\
Sem suplementação & $8,10 \mathrm{Ba}$ & $7,65 \mathrm{Ba}$ \\
\hline${ }^{(1)}$ Médias seguidas de letras iguais, maiúsculas nas colunas e minúsculas \\
nas linhas, não diferem entre si pelo teste Tukey, a 5\% de probabilidade.
\end{tabular}

\section{Referências}

ANDRADE, M.C.N. de; CALONEGO, F.W.; MINHONI, M.T. de A.; SEVERO, E.T.D.; KOPYTOWSKI FILHO, J. Avaliação do crescimento micelial de linhagens de shiitake, da produção em toras de eucalipto e de alterações físicas da madeira. Acta Scientiarum. Agronomy, v.29, p.23-27, 2007.

ANDRADE, M.C.N. de; SILVA, J.H. da; MINHONI, M.T. de A.; ZIED, D.C. Mycelial growth of two Lentinula edodes strains in culture media prepared with sawdust extracts from seven Eucalyptus species and three Eucalyptus clones. Acta Scientiarum. Agronomy, v.30, p.333-337, 2008.

BAYSAL, E.; PEKER, H.; YALINKILIÇ, M.K.; TEMIZ, A. Cultivation of oyster mushroom on waste paper with some added supplementary materials. Bioresource Technology, v.89, p.95-97, 2003.

BONONI, V.L.; CAPELARI, M.; TRUFEM, S.F.B. Cultivo de cogumelos comestíveis. 2.ed. São Paulo: Ícone, 1999. 206p.

DAS, N.; MUKHERJEE, M. Cultivation of Pleurotus ostreatus on weed plants. Bioresource Technology, v.98, p.2723-2726, 2007.

DONINI, L.P.; BERNARDI, E.; MINOTTO, E.; NASCIMENTO, J.S. do. Desenvolvimento in vitro de Pleurotus spp. sob a influência de diferentes substratos e dextrose. Arquivos do Instituto Biológico, v.72, p.331-338, 2005.

FURLAN, S.A.; VIRMOND, L.J.; MIERS, D.A.; BONATTI, E.M.; GERN, R.M.M.; JONAS, R. Mushroom strains able to grow at high temperatures and low $\mathrm{pH}$ values. World Journal of Microbiology and Biotechnology, v.13, p.689-692, 1997.

JONATHAN, S.G.; FASIDI, I.O.; AJAYI, A.O.; ADEGEYE, O. Biodegradation of Nigerian wood wastes by Pleurotus tuber-regium (Fries) Singer. Bioresource Technology, v.99, p.807-811, 2008.

MAZIERO, R. Substratos alternativos para o cultivo de Pleurotus spp. 1990. 136p. Dissertação (Mestrado) - Universidade de São Paulo, São Paulo.

NASCIMENTO, J.S. do; EIRA, A.F. da. Isolation and mycelial growth of Diehliomyces microsporus: effect of culture medium and incubation temperature. Brazilian Archives of Biology and Technology, v.50, p.587-595, 2007.

NYOCHEMBENG, L.M.; BEYL, C.A.; PACUMBABA, R.P. Optimizing edible fungal growth and biodegradation of inedible crop residues using various cropping methods. Bioresource Technology, v.99, p.5645-5649, 2008.

SALES-CAMPOS, C.; ABREU, R.L.S.; VIANEZ, B.F. Condições de uso e processamento de madeira nas indústrias madeireiras de Manaus, Amazonas, Brasil. Acta Amazonica, v.30, p.319-331, 2000.

WANG, D.; SAKODA, A.; SUZUKI, M. Biological efficiency and nutritional value of Pleurotus ostreatus cultivated on spent beer grain. Bioresource Technology, v.78, p.293-300, 2001.

ZADRAZIL, F. The ecology and industrial production of Pleurotus ostreatus, Pleurotus florida, Pleurotus cornucopiae and Pleurotus eryngii. In: INTERNATIONAL SCIENTIFIC CONGRESS ON THE CULTIVATION OF EDIBLE FUNGI, 9., 1974, Tokyo. Proceedings. Tokyo: Mushroom Science, 1974. p. 552-621

Recebido em 3 de junho de 2008 e aprovado em 13 de outubro de 2008 
